\title{
Antibiotic Sensitivity Pattern of Different Bacterial Species Isolated from Faecal Samples of Pups Affected with Canine Parvoviral Enteritis
}

\author{
M. Bhargavi ${ }^{1 *}$, B. Shobhamani ${ }^{2}$ K. Nalini Kumari ${ }^{2}$ and Ch. Srilatha ${ }^{3}$ \\ ${ }^{1}$ Department of Veterinary Medicine, NTR College of Veterinary Science, \\ Gannavaram, 521101, Andhra Pradesh, India \\ ${ }^{2}$ Department of Veterinary Medicine, ${ }^{3}$ Department of Veterinary Pathology, College of \\ Veterinary Science, Sri Venkateswara Veterinary University (SVVU), Tirupati - 517502, \\ Andhra Pradesh, India \\ *Corresponding author
}

\section{A B S T R A C T}

Keywords

Antibiogram, Bacteria, Canine parvoviral enteritis, Dogs.

Article Info

Accepted:

23 September 2017

Available Online:

10 October 2017
Among the viruses, infection with canine parvovirus 2 (CPV-2) was considered as highly contagious and causes acute haemorrhagic gastroenteritis and myocarditis in dogs. In the present study, faecal samples from fourteen pups affected with canine parvoviral enteritis were subjected to detailed bacteriological examination. It revealed the presence of bacterial species like E. coli, Salmonella spp., Klebsiella spp., Pseudomonas spp., Staphylococcus spp., and Streptococcus spp. in different combinations along with CPV infection. Invitro antibiotic sensitivity test of whole cultures revealed highest sensitivity to amikacin $(85.71 \%)$ followed by other antibiotics such as cefepime, chloramphenicol, cefotaxime, ceftriaxone, levofloxacin, ceftazidime and amoxycillin with clavulanic acid and all the samples exhibited resistance to ampicillin and metronidazole.

\section{Introduction}

Canine parvovirus $2(2 \mathrm{a}, 2 \mathrm{~b}$ and $2 \mathrm{c})$ is one of the most significant viral causes of acute hemorrhagic gastroenteritis and myocarditis in canine population, which is highly contagious and the disease may be often fatal. Acute enteritis is the most common clinical manifestation of the disease especially in puppies' upto 6 months of age (Goddard and Leisewitz, 2010) whereas myocarditis is very rarely seen unless infection occurs in utero or in puppies less than 8 weeks old born to unvaccinated bitches (Hoskins, 1997). Factors that predispose puppies to parvoviral infection include lack of protective immunity, intestinal parasites, overcrowding, unhygienic and stressful environmental conditions. CPV-2 spreads rapidly among dogs via faecal route (direct transmission) or through oronasal exposure to fomites contaminated with infective faeces (indirect transmission) (Johnson and Smith., 1983). The main source of infection seems to be the faeces of infected dogs, as $10^{9}$ virus particles can be shed in one gram of faeces during the acute enteric form of the disease. Faecal shedding of virus may continue for a maximum period of 3 to 4 weeks after clinical or subclinical disease. Intestinal tract damage secondary to viral 
infection increases the risk of bacterial translocation leading to coliform septicemia and development of systemic inflammatory response syndrome that can progress to septic shock. The purpose of the present study was to determine the various types of bacterial species in faecal samples of pups affected with canine parvoviral enteritis and to study the in vitro antibiotic sensitivity pattern of whole cultures to different antibiotics.

\section{Materials and Methods}

In the present study, a total of twenty four faecal samples were collected with sterile swabs from pups presented with symptoms suggestive of canine parvoviral enteritis (dullness, pyrexia, vomiting, bloody foul smelling diarrhoea etc.,) and subjected to sandwich lateral flow immune chromatography assay (Scan Vet ${ }^{\mathrm{TM}}$ PARVO kit).

\section{Isolation and identification of bacteria}

Faecal samples from fourteen CPV positive pups were inoculated simultaneously into nutrient broth and selenite broth and incubated at $37^{\circ} \mathrm{C}$ for $24 \mathrm{hrs}$ aerobically, then a loopful of bacterial culture was streaked on nutrient agar plates. Based on morphology and from Gram's staining, cultures were inoculated into specific or selective media like MacConkey agar, Mannitol salt agar, Eosin- methylene blue agar, Edwards medium and on xylose lysine deoxycholate (XLD) agar medium. Pathogenecity was tested by inoculating on blood agar.

Primary identification of bacteria was done based on colony morphology, type of hemolysis, Gram's staining, biochemical characteristics and pure cultures were identified upto genus level as per the Bergy's Manual of Determinative Bacteriology (Holt et al., 2000).

\section{Antibiotic sensitivity test}

The antibiotic sensitivity test was performed on the faecal whole cultures from nutrient broth in vitro by Kirby Bauer disc diffusion method on Mueller Hinton Agar (MHA) plates. The antibiotics used in present study were Amikacin (AK), Amoxyclav (AMC), Ampicillin (AMP), Cefepime (CPM), Cefotaxime (CTX), Ceftazidime (CAZ), Ceftriaxone (CTR), Chloramphenicol (C), Levofloxacin (LE) and Metronidazole (MT). The sensitivity pattern was read by measuring the diameter of zone of inhibition corresponding to different antibiotics in millimeter as per the interpretation chart provided by the manufacturer.

\section{Results and Discussion}

Out of twenty four pups in the present study, fourteen pups were found to be positive for CPV infection with sandwich lateral flow immunochromatography assay. Earlier, in many studies immunochromatography based test kits were employed for the detection of parvovirus in faecal samples of dogs, since it is a rapid, simple, reproducible and sensitive diagnostic test (Esfandiari and Klingeborn, 2001, Pillai and Deepa, 2010, Filipov et al., 2011 and Dongre et al., 2013).

In the present study, culturing of faecal samples from fourteen CPV affected dogs revealed the presence of gram negative bacteria such as E.coli, Salmonella spp., Klebsiella spp., Pseudomonas spp. and gram positive bacteria such as Staphylococcus spp. and Streptococcus spp. in different combinations along with CPV infection (Table 1). Cultural and biochemical characteristics of different species of bacteria isolated from faecal samples of affected dogs are depicted in Figure 1. Invasion of secondary bacteria in the present study might be due to leukopenia and compromise of 
immune system. CPV causes necrosis of gutassociated lymphoid tissue resulting diminished local immunity to infectious agents and predisposing to bacterial infection, as suggested by Turk et al., (1992). Similarly secondary bacterial infection with $E$. coli (Isogai et al., 1989, Zschock et al., 1989 and Basava reddy., 2013), Clostridium perfringens (Turk et al., 1992 and Hoskins., 2006), Campylobacter spp. (Sandstedt and Wierup., 1981, Hagiwara et al., 1996 and Hoskins., 2006), Klebsiella spp. and Staphylococcus spp. (Basava reddy., 2013), and Salmonella spp (Hoskins., 2006 and Basava reddy., 2013) was reported from isolation studies on faecal samples of dogs with parvoviral enteritis. Koutinas et al., (1998) isolated E. coli, Staphylococcus spp., Enterococcus durans and Corynebacterium spp. from urine samples of CPV affected dogs, and stated that it might be due to the faecal contamination of genital organs. Other species of bacteria like Serratia spp., Acinobacter anitratus, Citrobacter freundii, Staphylococcus intermedius, Streptococcus spp., Klebsiella pnemoniae, K.oxytoca, Escherichia coli and Enterobacter spp. were also isolated from bacteriological culture of swabs obtained from intravenous catheters placed to parvoviral infected dogs (Lobetti et al., 2002 and Greene and Decaro, 2012).

Nivy et al., (2011) isolated an unusually resistant $E$. coli strain from the cerebrospinal fluid of a CPV affected dog and stated that dogs with CPV infection have an increased risk of secondary bacterial infections due to neutropenia and immunosuppression.

Table.1 Mixed infection of CPV with different bacterial species

\begin{tabular}{|l|c|c|}
\hline \multicolumn{1}{|c|}{ Type of isolates } & No. of positive faecal samples & Percent $(\%)$ \\
\hline CPV + E.coli + Staphylococcus spp. & 3 & 21.43 \\
\hline CPV + E.coli + Streptococcus spp. & 2 & 14.28 \\
\hline CPV + Salmonella spp. + Staphylococcus spp. & 3 & 21.43 \\
\hline CPV + Salmonella spp. + Streptococcus spp. & 1 & 7.14 \\
\hline CPV + Klebsiella spp.+ Streptococcus spp. & 2 & 14.28 \\
\hline CPV + Pseudomonas spp. + Staphylococcus spp. & 3 & 21.43 \\
\hline
\end{tabular}

Table.2 Antibiogram of the microbial isolates emanating from CPV affected dogs ( $\mathrm{n}=14)$

\begin{tabular}{|l|l|l|l|l|l|l|l|}
\hline \multirow{2}{*}{ S. No } & \multirow{2}{*}{ Drug } & \multicolumn{2}{|l|}{ Sensitivity } & \multicolumn{2}{l|}{ Intermediate } & \multicolumn{2}{l|}{ Resistant } \\
\cline { 3 - 8 } & No. & $\%$ & No. & $\%$ & No. & $\%$ \\
\hline 1. & Ampicillin & 0 & 0.00 & 0 & 0.00 & 14 & 100.00 \\
\hline 2. & Amikacin & 12 & 85.71 & 1 & 7.14 & 1 & 7.14 \\
\hline 3. & Amoxyclav & 1 & 7.14 & 3 & 21.43 & 10 & 71.43 \\
\hline 4. & Cefepime & 7 & 50.00 & 4 & 28.57 & 3 & 21.43 \\
\hline 5. & Cefotaxim & 5 & 35.71 & 3 & 21.43 & 6 & 42.86 \\
\hline 6. & Ceftazidime & 2 & 14.28 & 6 & 42.86 & 6 & 42.86 \\
\hline 7. & Ceftriaxone & 5 & 35.71 & 5 & 35.71 & 4 & 28.57 \\
\hline 8. & Chloramphenicol & 6 & 42.86 & 3 & 21.43 & 5 & 35.71 \\
\hline 9. & Levofloxacin & 5 & 35.71 & 3 & 21.43 & 6 & 42.86 \\
\hline 10. & Metronidazole & 0 & 0.00 & 0 & 0.00 & 14 & 100.00 \\
\hline
\end{tabular}


Fig.1 Cultural and biochemical characters of different bacterial species

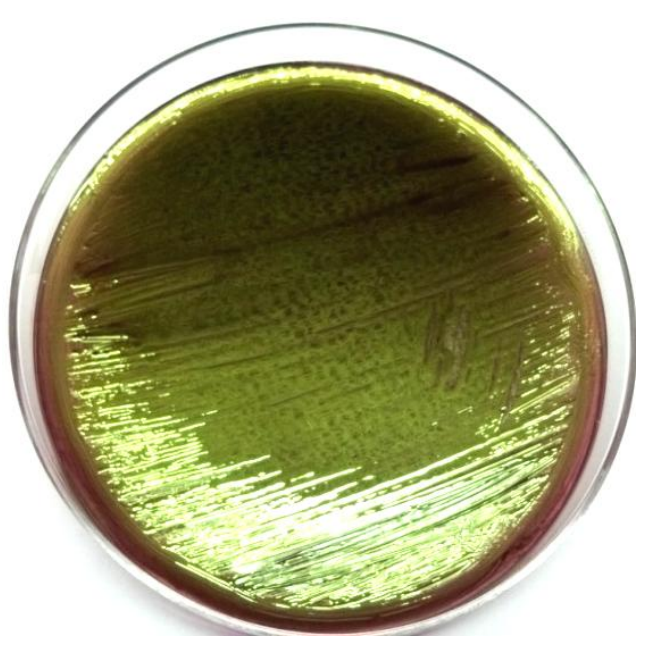

E. coli on EMB agar (metallic sheen)

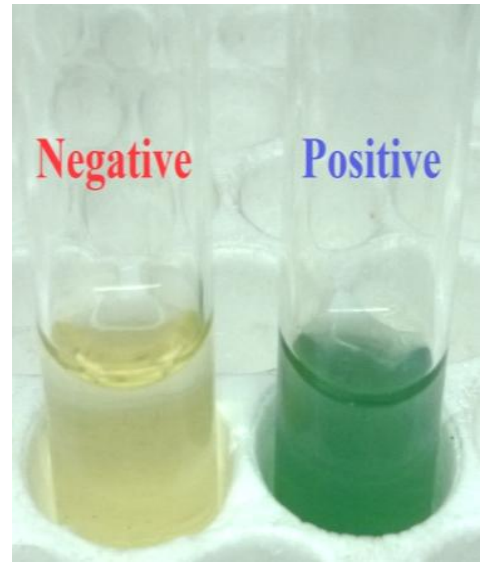

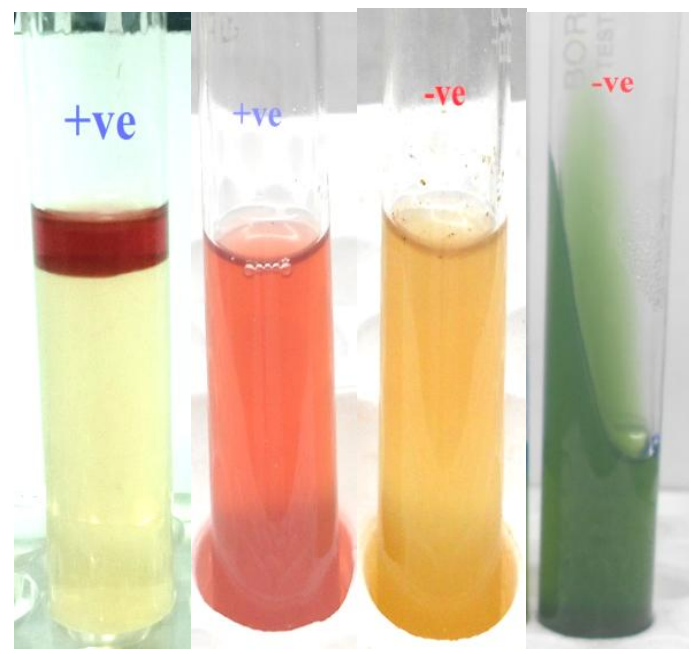

$\mathrm{IMViC}+,+,-,-$ of $E$. coli

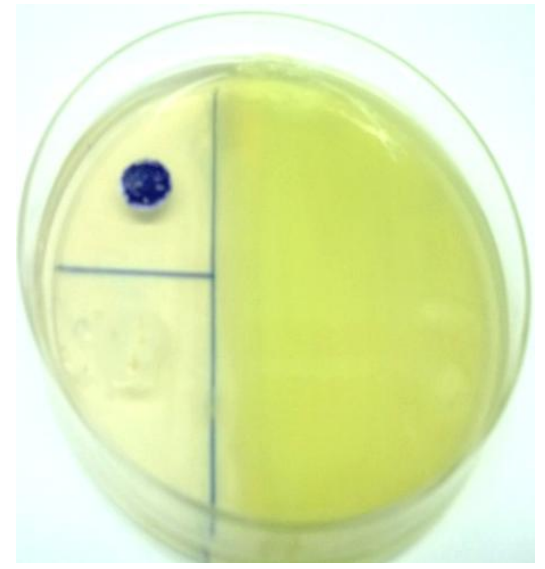

Pseudomonas spp. in nutrient broth and Catalase +ve; Oxidase +ve
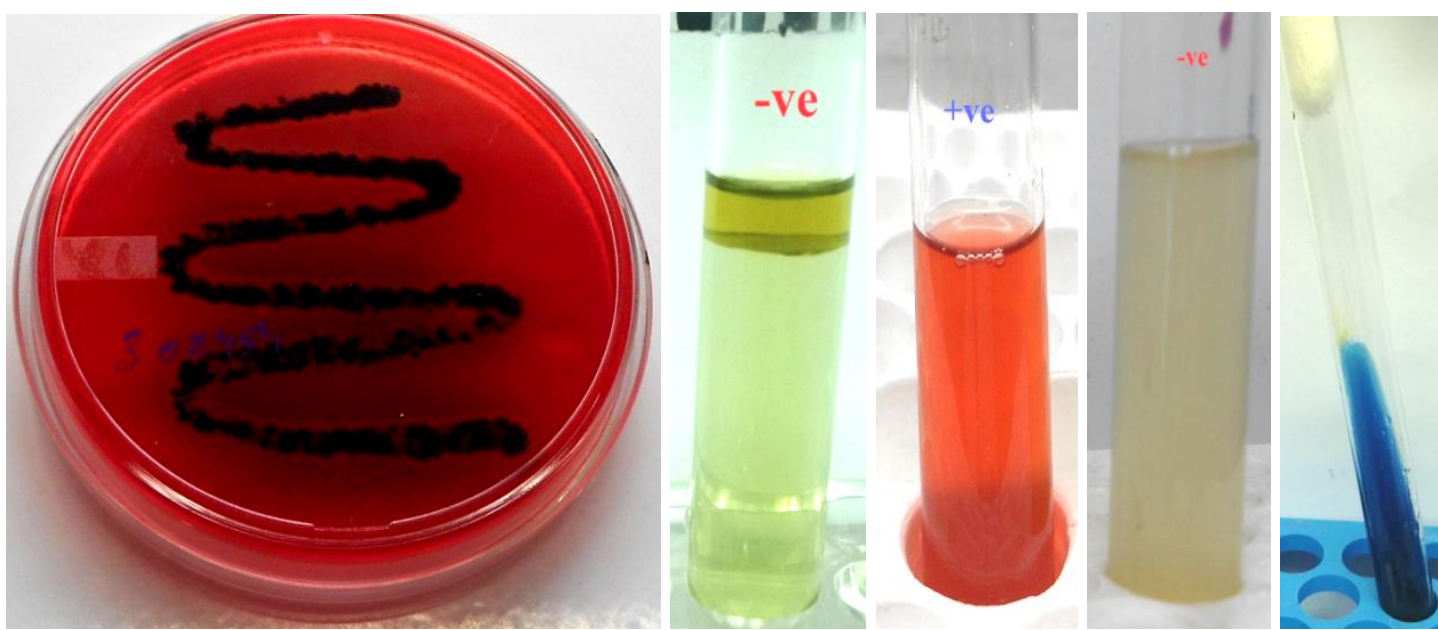

Salmonella sps on XLD agar and IMViC: -, +, -, + 

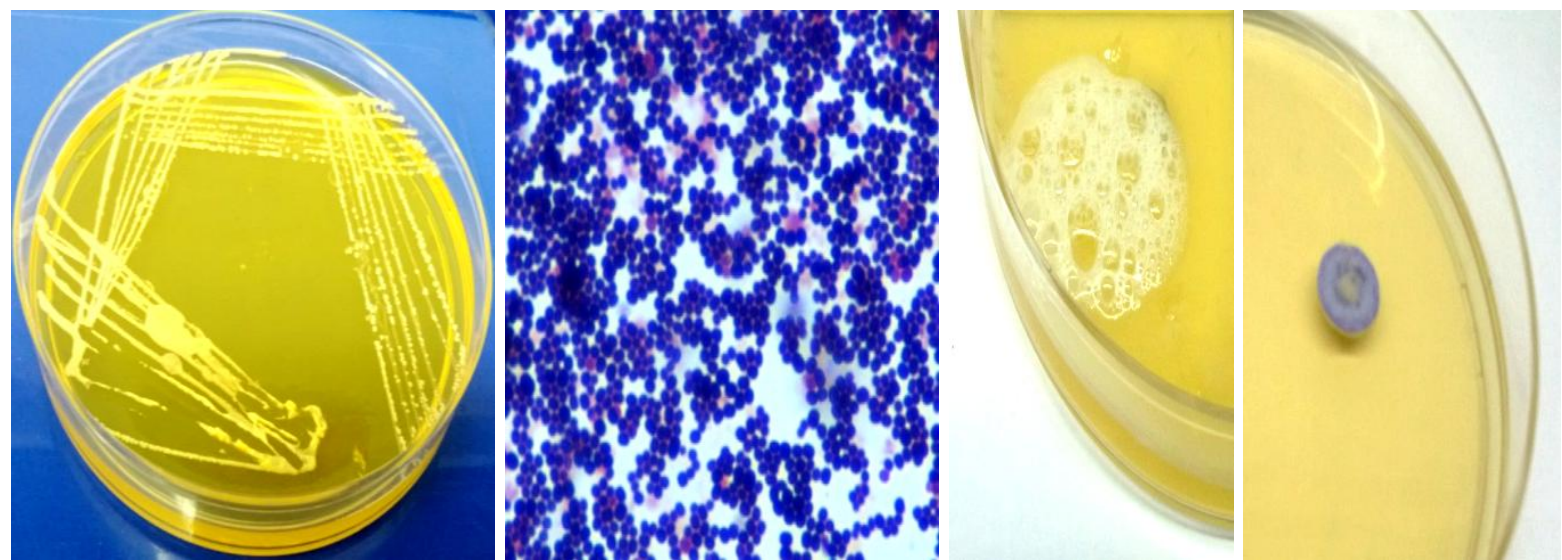

Staphylococcus spp. on Mannitol salt agar; Gram's staining; Catalase and Oxidase +ve
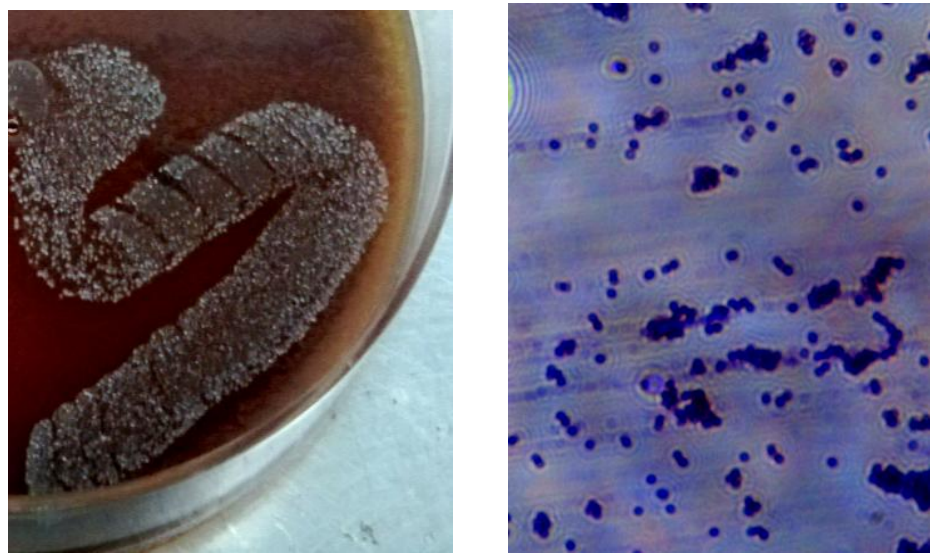

Streptococcus spp. colonies on Edward's and Gram's staining

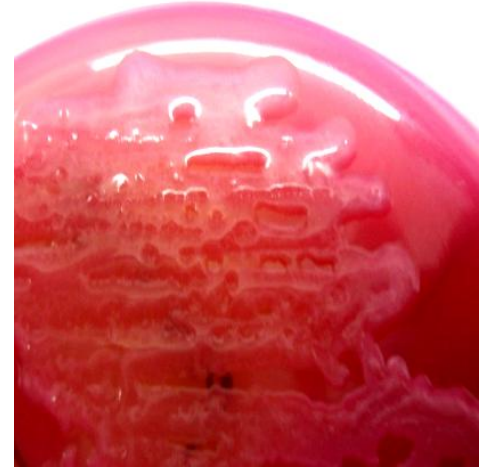

Klebsiella spp on Macconkey agar medium

Fig.2 ABST (Antibiotic sensitivity pattern of bacteria to different antibiotics)

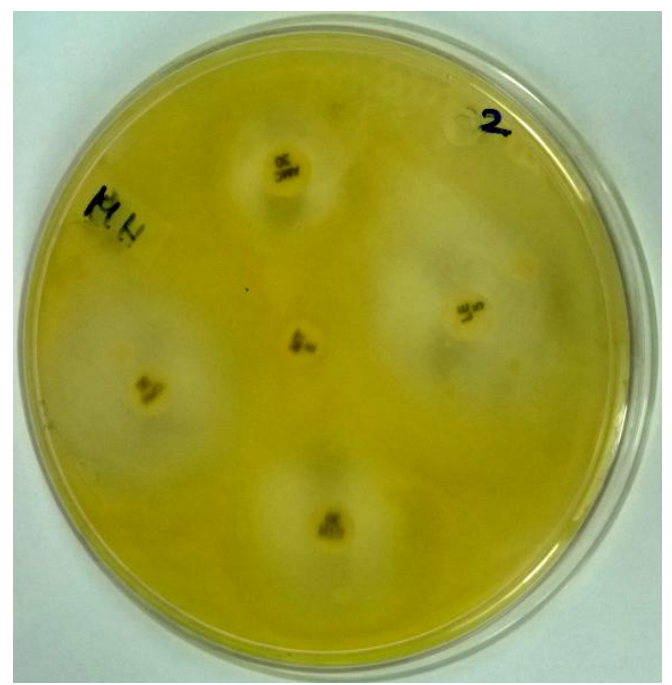

Sensitivity to Ceftriaxone

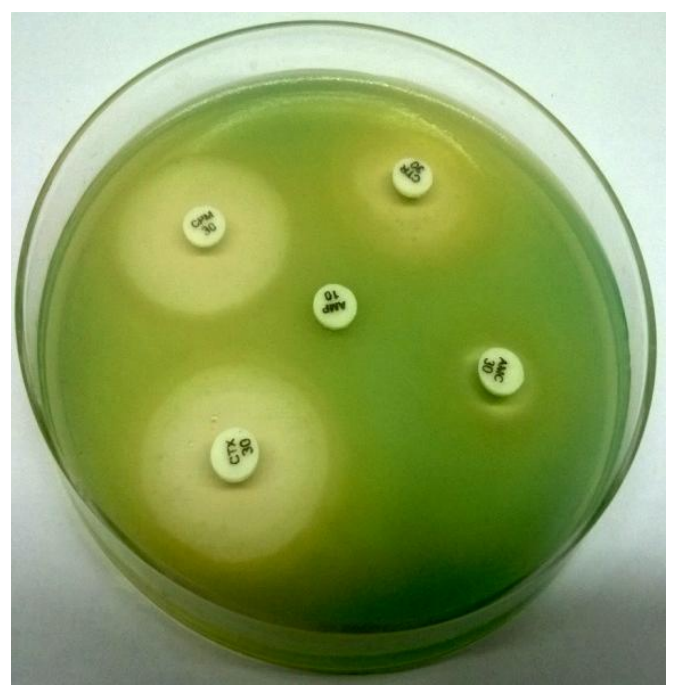

Sensitivity to Cefepime and Cefotaxime 


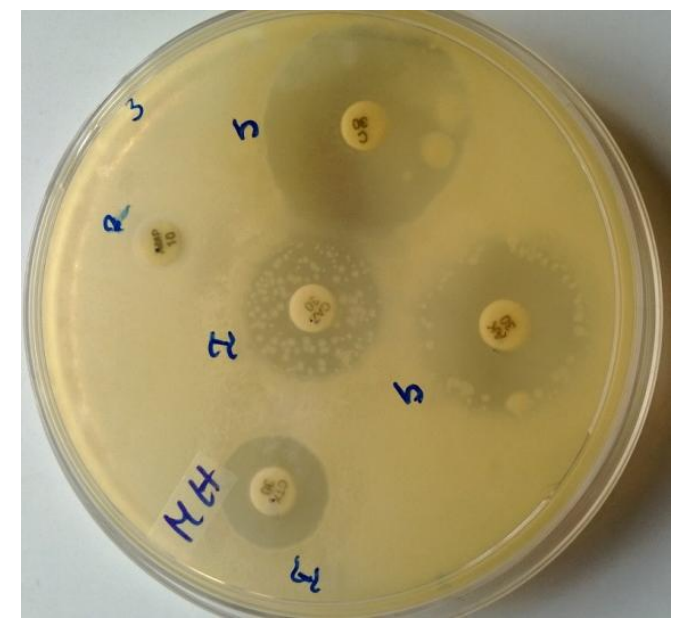

Sensitivity to Amikacin

The antibiogram of whole cultures present in the faecal samples of fourteen CPV affected dogs is presented in Table 2 and Figure 2. In the present study, amikacin, an aminoglycoside showed highest sensitivity of 85.71 percent due to its predominant activity against Gram-negative aerobic bacteria and Staphylococcus spp., are usually susceptible to aminoglycosides but most other Grampositive aerobes are not. Amikacin is particularly important in treating serious Pseudomonas spp. and other Gram- negative infections in immunosuppressed patients (Maddison et al., 2008).

Earlier, Dutta et al., (2008) reported 72.22 percent of sensitivity of amikacin to Salmonella spp. isolated from diarrhoeic dogs. Cefepime in the present study showed 50 percent sensitivity, is a fourth generation cephalosporin which had increased activity against both Gram- positive and Gramnegative bacteria, moderate activity against Pseudomonas spp. and enhanced activity against Staphylococcus spp. (Maddison et al., 2008). In the present study, chloramphenicol had $42.86 \%$ sensitivity. Earlier, Salmonella organisms isolated from diarrhoeic dogs exhibited 72.22 percent of sensitivity to chloramphenicol, as was reported by Dutta et al., (2008). Sharma (2003) reported 87.50 percent of sensitivity of chloramphenicol against bacterial isolates from diarrhoeic dogs. Chloramphenicol is bacteriostatic for most Gram- positive and many Gramnegative aerobic bacteria but can be bactericidal against some very sensitive bacteria. Acquired resistance occurs in many species, especially where chloramphenicol is in common use. Pseudomonas aeruginosa, Escherichia, Klebsiella, Enterobacter, Salmonella and Proteus show patterns of plasmid-mediated resistance (Maddison et al., 2008). The in vitro drug sensitivity of both ceftriaxone and cefotaxime was found to be 35.71 percent in the present study.

Both included under third generation cephalosporin group, had decreased Grampositive but increased Gram- negative activity (susceptible Gram- negative bacteria include Escherichia coli, Klebsiella spp., Proteus spp., Haemophilus spp., Actinobacillus spp., Salmonella spp.) as stated by Maddison et al., (2008). But the less sensitivity in the present study could be due to the involvement of Pseudomonas spp. against which the sensitivity is variable (Maddison et al., 2008) and presence of Gram- positive organisms and wide spread use of these antibiotics since quite a long period. Earlier Dutta et al., (2007) reported 55.56 percent of sensitivity of cefotaxime to Salmonella isolates from diarrhoeic dogs. Cefotaxime exhibited 85.03 
percent of sensitivity to bacteria isolated from diarrhoeic dogs (Singh, 2008). In the present study, the in vitro drug sensitivity of amoxicillin with clavulanic acid was found to be 7.14 percent. Amoxicillin-clavulanate, in contrast to amoxicillin alone, has activity against penicillinase-producing Staphylococcus and has enhanced activity against Gram-negative pathogens. However, Enterobacter, Citrobacter, Pseudomonas aeruginosa, Serratia and methicillin-resistant Staphylococcus are resistant (Maddison et al., 2008). Emergence of many resistant strains of Gram- negative bacteria and increasing prevalence of Klebsiella pneumoniae, Pseudomonas aeruginosa and Enterobacter spp as pathogens might be responsible for decreased spectrum of amoxicillin as they are intrinsically nonsusceptible to aminopenicillins (Maddison et al., 2008).

Ampicillin and metronidazole exhibited 100 percent resistance, which might be attributed to the frequent and indiscriminate use of these antimicrobial agents. Previously Dutta et al., (2007) reported 100 percent of resistance of ampicillin to Salmonella isolates and Sharma (2003) reported cent percent resistance of metronidazole against bacteria isolated from diarrhoeic dogs.

The present study concluded that, the most common bacteria involved were of Gramnegative species (E. coli, Salmonella spp., Klebsiella spp., and Pseudomonas spp.) and few Gram- positive species (Staphylococcus spp., and Streptococcus spp.,). Antibiogram studies revealed 85.71 percent of sensitivity to amikacin and 35.71 percent to ceftriaxone.

\section{References}

Basava Reddy, K., 2013. Clinico-epidemiological studies on canine parvoviral infection in and around Tirupati. M.V.Sc thesis submitted to Sri Venkateswara Veterinary Univesity, Tirupati.
Dongre, J., Mehta, H. K., and Maheswari, P. 2013. Rapid diagnosis and clinical management of canine parvovirus infection. Intas polivet. 14 (1): 155-156.

Dutta, P. R., Phukan, A., Borah, P., and Hazarika, G. C. 2007. In vitro drug sensitivity pattern of salmonella isolated from diarrhoeic dogs. Indian Journal of Veterinary Medicine. 27(2): 147-148.

Dutta, P. R., Phukan, A., Borah, P., and Hazarika, G. C. 2008. Pathogenicity and In-vitro drug sensitivity pattern of salmonella isolated from diarrhoeic dogs. Indian Veterinary Journal. 85(11): 1223-1224.

Esfandiari, J., and Klingeborn, B. 2000. A comparative study of a new rapid and onestep test for the detection of parvovirus in feces from dogs, cats and mink. Journal of Veterinary Medicine. 47: 145-153.

Filipov, C., Decaro, N., Desario, C., Amorisco, F., Sciarretta, R., and Buonavoglia, C. 2011. Canine parvovirus epidemiology in Bulgaria. Journal of Veterinary Diagnostic Investigation. 23:152-154.

Goddard, A., and Leisewitz, A. L. 2010. Canine Parvovirus. Vet Clin Small Anim. 40: 1041-1053.

Greene, C. E., and Decaro, N. 2012. Canine viral enteritis. In: Greene C E, Infectious diseases of the dog and cat, Fourth edition, W.B. Saunders, Elsevier., pp. 67- 74.

Hagiwara, M. K., Mamizuka, E. M., and PavanM-de-F, B. 1996. Role of intestinal flora in acute hemorrhagic gastroenteritis (parvovirus infection) of dogs. Brazilian Journal of Veterinary Research and Animal Science. 33(2): 107-109.

Holt, J. G., Krieg, N. R., Sneath, P. H. A., Staley, J. T., and Williams, S. T. 2000. Bergey's Manual of Determinative Bacteriology. Ninth edition, Lippincott Williams and Wilkins, Philadelphia, USA.

Hoskins, J. D., 1997. Update on canine parvoviral enteritis. Vet Med. 92(8):694-709.

Hoskins, J. D., 2006. Canine viral enteritis. In: Greene C E, Infectious diseases of the Dog and Cat, $3^{\text {rd }}$ edition, W.B. Saunders Co., Phildelphia, pp 40-45.

Isogai, E., Isogai, H., Onuma, M., Mizukoshi, N., Hayashi, M., and Namioka, S. 1989. Escherichia coli associated endotoxemia in 
dogs with parvovirus infection. Nihon Juigaku Zasshi.51(3): 597-606.

Johnson, R. H., and Smith, J. R. 1983. Epidemiology and pathogenesis of canine parvovirus. Aust Vet Pract. 13(1):31.

Koutinas, A. F., Heliadis, N., Saridomichelakis, M. N., Leontides, L., Terpsidis, K., and Christodoulou, C. 1998. Asymptomatic bacteriruria in puppies with canine parvovirus infection: a cohort study. Veterinary Microbiology. 63: 109-116.

Lobetti, R. G., Joubert, K. E., Picard, J., Carstens, J., and Pretorius, E. 2002. Bacterial colonisation of intravenous catheters in young dogs suspected to have parvoviral enteritis. Journal of American Veterinary Medical Association. 220 (9): 1321- 1324.

Maddison, J. E., David, A., Watson, J., and Elliott, J. 2008. In: Maddison J E, Page S W and Church D B. 2008. Small Animal Clinical Pharmacology, second edition, W.B. Saunders, Philadelphia, pp. 148-185.

Nivy, R., Hahn, S., Perl, S., Karnieli, A., Karnieli, O., and Aroch, I. 2011. A Fatal Outbreak of Parvovirus Infection: First Detection of Canine Parvovirus Type 2c in Israel with Secondary Escherichia coli Septicemia and Meningoencephalitis. Israel Journal of Veterinary Medicine. 66 (3): 96-102.

Pillai, U. N., and Deepa, P. M. 2010. Rapid diagnosis and treatment of canine parvoviral enteritis. Intas Polivet. 11(II):
348-349.

Sandstedt, K., and Wierup, M. 1981. Concommitant occurrence of Campylobacter and parvovirus in dogs with gastroenteritis. Veterinary Research Communication. 4(4): 271- 273.

Sharma, A., 2003. Clinical and therapeutic studies on canine gastroenteritis. M.V.Sc.Thesis, Department of Veterinary Medicine, CSK Himachal Pradesh Krishi Vishvavidyalaya, Palampur, India. pp 5-35, 143-164 and 170.

Singh, G., 2008. Studies on etiological agents of canine diarrhoea with special reference to canine parvovirus. M.V.Sc Thesis, Department of Veterinary Microbiology and Immunology, CSK Himachal Pradesh Krishi Vishvavidyalaya, Palampur, India. pp 40-56.

Turk, J., Fales, W., Miller, M., Pace, L., Fischer, J., Johnson, G., Kreeger, J., Turnquist, S., Pittman, L., Rottinghaus, A., and Gosser, H. 1992. Enteric Clostridium perfringens infection associated with parvoviral enteritis in dogs: 74 cases (1987-1990). Journal of the American Veterinary Medical Association. 200(7): 991- 994.

Zschock, M., Herbst, W., Lange, H., Hamann, H P., and Schliesser, T. 1989. Results from microbiological studies (bacteriology and electron microscopy) of diarrhoea in puppies. Tierarztliche Praxis. 17(1): 93- 95.

\section{How to cite this article:}

Bhargavi, M., B. Shobhamani, K. Nalini Kumari and Srilatha, Ch. 2017. Antibiotic Sensitivity Pattern of Different Bacterial Species Isolated from Faecal Samples of Pups Affected with Canine Parvoviral Enteritis. Int.J.Curr.Microbiol.App.Sci. 6(10): 2875-2882. doi: https://doi.org/10.20546/ijcmas.2017.610.338 